\title{
A 70-year-old male having advanced prostate cancer presenting with hypercalcemia and diffuse osteoblastic bone metastases: a case report
}

\author{
Wan-Hsiu Liao ${ }^{1}$, Sheng-Hsiang Lin*2 and Tsu-Tuan $\mathrm{Wu}^{2}$
}

\begin{abstract}
Address: ${ }^{1}$ Department of Family Medicine, Taipei County Hospital, Taipei county, Taiwan (ROC) and ${ }^{2}$ Department of Internal Medicine, Taipei County Hospital, Taipei county, Taiwan (ROC)

Email: Wan-Hsiu Liao - liaowh1976@gmail.com; Sheng-Hsiang Lin* - linsh01@gmail.com; Tsu-Tuan Wu - 00291@tpch.gov.tw

* Corresponding author
\end{abstract}

Published: 14 January 2009

Cases Journal 2009, 2:54 doi:10.1 186/1757-1626-2-54

This article is available from: http://www.casesjournal.com/content/2/1/54

(c) 2009 Liao et al; licensee BioMed Central Ltd.

This is an Open Access article distributed under the terms of the Creative Commons Attribution License (http://creativecommons.org/licenses/by/2.0), which permits unrestricted use, distribution, and reproduction in any medium, provided the original work is properly cited.
Received: 17 December 2008

Accepted: 14 January 2009

\begin{abstract}
Background: Bony metastases were occasionally the initial presentations of malignancy. Overlooking of bony changes on radiographs in cancer patients with non-specific clinical symptoms may lead to delayed diagnosis.
\end{abstract}

Case presentation: We presented a 70-year-old male having hypercalcemia and diffuse osteoblastic bone metastases on routine plain films. Finally, prostate cancer was diagnosed with a prostate needle biopsy.

Conclusion: Although the modern radionuclide bone scanning is useful in diagnosis, osteoblastic bone changes are occasionally seen in plain films, which are frequently overlooked. To avoid delayed diagnosis, bony structures should be carefully examined in all plain-film radiographs.

\section{Background}

Bone metastases of malignant neoplasm are common, especially in breast, lung and prostate cancer. Bone metastases of prostate cancer are usually osteoblastic which might be related to osteoblasts [1]. The recognition of bony changes in patients with prostate cancer may help in initially diagnosis, making treatment strategy and prognosis evaluation [2].

\section{Case presentation}

A 70-year-old man presented with poor appetite and general malaise of two month's duration. Physical examination revealed mildly distended abdomen and hypoactive bowel sounds. Hemogram showed high white blood cell count $(22070 / \mu \mathrm{l})$ with $91.5 \%$ segment form and low hemoglobin level $(7.0 \mathrm{~g} / \mathrm{dl})$. Biochemical examination showed elevated serum calcium level $(2.7 \mathrm{mmole} / \mathrm{l})$. Urinary analysis showed hematuria (numerous red blood cells per high power field in sediment examination). The serum prostate-specific antigen (PSA) was $100 \mathrm{ng} / \mathrm{ml}$. A chest radiograph (figure 1) showed diffuse osteoblastic bone lesions. In addition to dilated bowel loops with feces, an abdominal radiograph (figure 2) showed multiple patchy osteoblastic changes of bones. A malignant disease with multiple osteoblastic bone metastases was highly suspected. Finally, prostate cancer was diagnosed with a prostate needle biopsy. He received bilateral orchiectomy and hormone therapy for stage IV disease. Unfortunately, he passed away 1 month later because of urosepsis. 


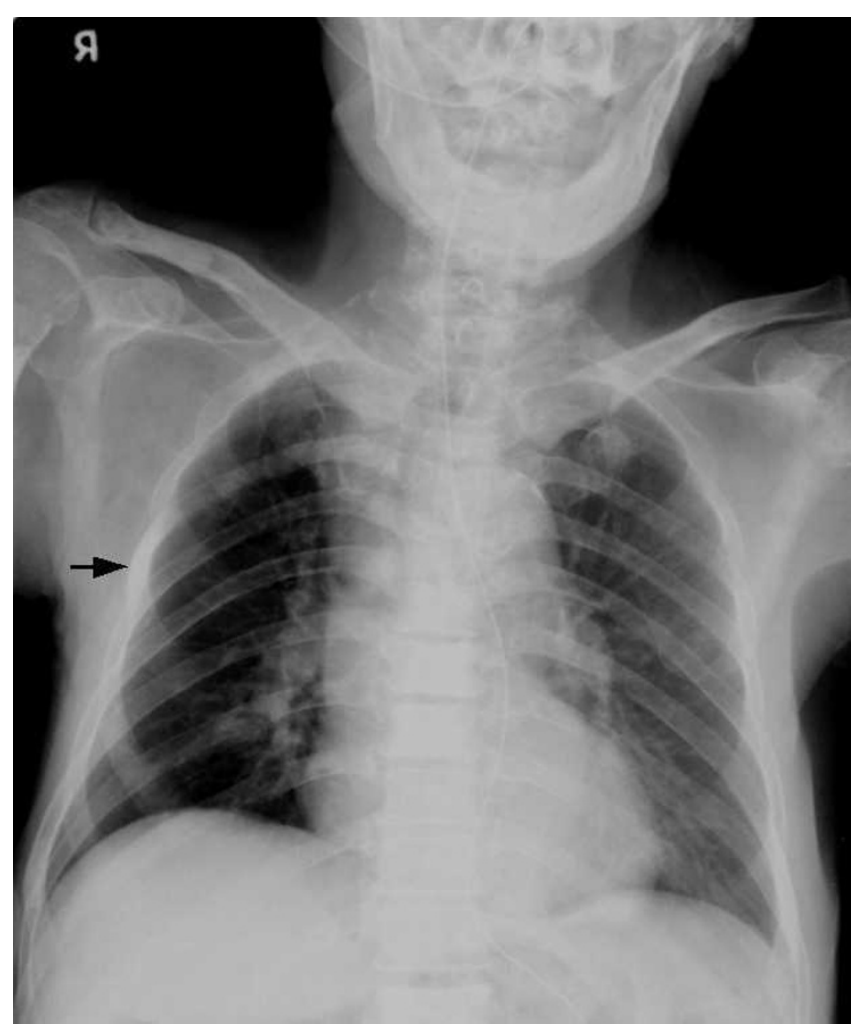

Figure I

Chest radiograph showing osteoblastic changes of spine, scapulae, clavicles and ribs (arrow: right 4th rib with more conspicuous change).

\section{Discussion}

Prostate cancer frequently metastasised to vertebrae and pelvis, where it produced predominantly osteoblastic lesions and local bone formation, and adversely affected quality of life and mortality [2]. In these patients, curative therapy was impossible and palliative treatment became the only option. Besides, bone metastatic prostate cancer could lead to disturbances of calcium metabolism and the presence of hypercalcemia was significantly associated with poor prognosis [3]. To date no definite benefit of bone targeted therapy was evidenced, and further investigation was needed [4].

Currently, conventional technetium-99m methylene diophosphate (Tc-99m MDP) bone scan and positron emission tomography with 18F-2-deoxyglucose (FDG-PET) were popular in the detection of malignant bone metastases [5]. In addition, whole body magnetic resonance imaging using diffusion-weighted images was shown to be an alternative to detect bone metastasis [6]. However, osteolytic or osteoblastic bone metastases were occasionally seen in routine plain-film radiographs. Identification of bony changes in plain film may contribute to the initial diagnosis of metastatic cancer

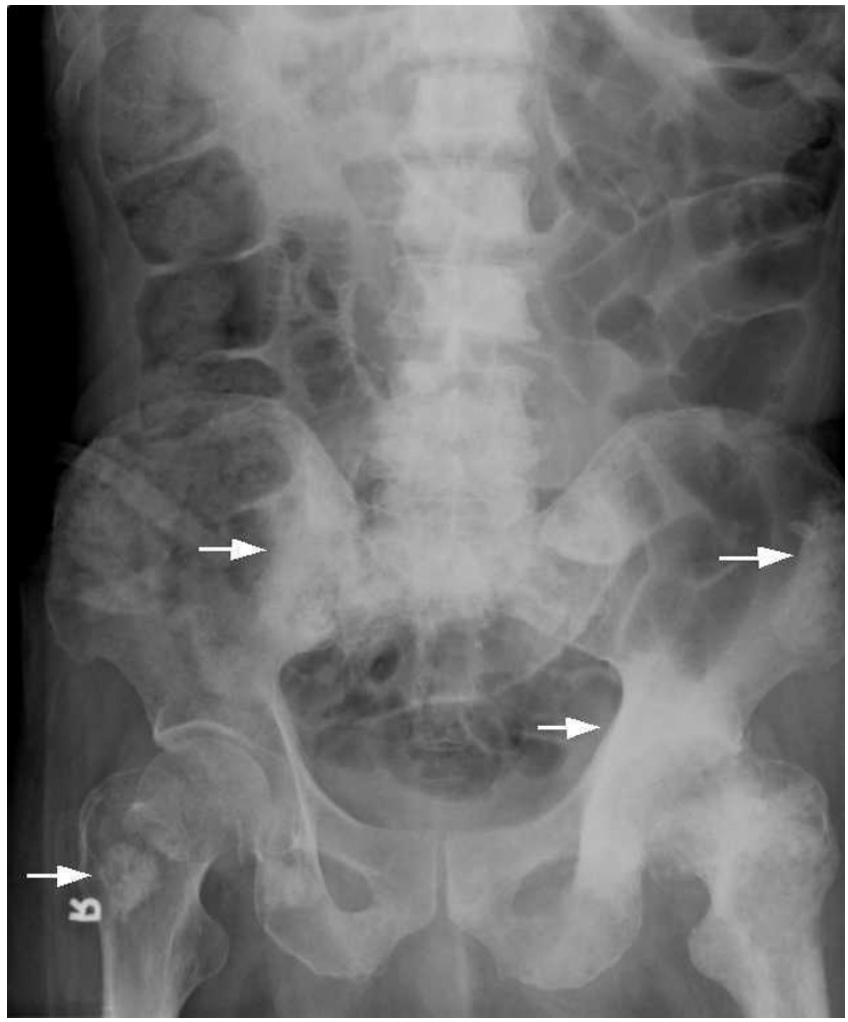

Figure 2

Abdominal radiograph showing osteoblastic changes of spine, pelvic and femoral bones (arrows).

\section{Conclusion}

Although the modern radionuclide bone scanning is useful in diagnosis, osteoblastic bone changes are occasionally seen in plain films, which are frequently overlooked. To avoid delayed diagnosis, bony structures should be carefully examined in all plain-film radiographs.

\section{Abbreviations}

PSA: prostate-specific antigen; Tc-99m MDP: technetium99m methylene diophosphate; FDG-PET: positron emission tomography with 18F-2-deoxyglucose.

\section{Consent}

A fully informed written consent was obtained form the patient family for the publication of this case and accompanying images. A copy of the written consent is available for review by the Editor-in-Chief of this journal.

\section{Competing interests}

The authors declare that they have no competing interests. 


\section{Authors' contributions}

WHL, SHL and TTW have made significant contributions by making diagnosis and intellectual input in the case and writing the manuscript.

\section{References}

I. Choueiri MB, Tu SM, Yu-Lee LY, Lin SH: The central role of osteoblasts in the metastasis of prostate cancer. Cancer Metastasis Rev 2006, 25:601-9.

2. Saad F, Clarke N, Colombel M: Natural history and treatment of bone complications in prostate cancer. Eur Urol 2006, 49:429-40.

3. Tucci M, Mosca A, Lamanna G, Porpiglia F, Terzolo M, Vana F, Cracco C, Russo L, Gorzegno G, Tampellini M, Torta M, Reimondo G, Poggio M, Scarpa RM, Angeli A, Dogliotti L, Berruti A: Prognostic significance of disordered calcium metabolism in hormone-refractory prostate cancer patients with metastatic bone disease. Prostate Cancer Prostatic Dis in press.

4. Bradley DA, Hussain M, Dipaola RS, Kantoff P: Bone directed therapies for prostate cancer. J Urol 2007, 178:S42-8.

5. Kao CH, Hsieh JF, Tsai SC, Ho YJ, Yen RF: Comparison and discrepancy of I 8F-2-deoxyglucose positron emission tomography and Tc-99m MDP bone scan to detect bone metastases. Anticancer Res 2000, 20:2189-92.

6. Nakanishi K, Kobayashi M, Nakaguchi K, Kyakuno M, Hashimoto N, Onishi H, Maeda N, Nakata S, Kuwabara M, Murakami T, Nakamura $\mathrm{H}$ : Whole-body MRI for detecting metastatic bone tumor: diagnostic value of diffusion-weighted images. Magn Reson Med Sci 2007, 6:147-55.

Publish with Bio Med Central and every scientist can read your work free of charge

"BioMed Central will be the most significant development for disseminating the results of biomedical research in our lifetime. "

Sir Paul Nurse, Cancer Research UK

Your research papers will be:

- available free of charge to the entire biomedical community

- peer reviewed and published immediately upon acceptance

- cited in PubMed and archived on PubMed Central

- yours - you keep the copyright 